\title{
Projeções populacionais em pequenas áreas: uma avaliação comparativa de técnicas de extrapolação matemática
}

\author{
Reinaldo Onofre dos Santos* \\ Alisson Flávio Barbieri ${ }^{\star *}$
}

\begin{abstract}
A investigação do tamanho e distribuição futuros de uma população é de relevância central para estudiosos de população que se ocupam de questões relacionadas ao planejamento regional. 0 objetivo central deste artigo é discutir, de forma crítica e propositiva, algumas técnicas de extrapolação matemática frequentemente utilizadas para a projeção em pequenas áreas, no sentido de contribuir para os instrumentais analíticos de demógrafos e planejadores. Projeções populacionais para pequenas áreas são um desafio para os planejadores em função da instabilidade de suas predições e do conflito com a necessidade eminente para a construção de políticas públicas. Assim, este trabalho apresenta a aplicação de cinco técnicas de projeção para pequenas áreas, bem como algumas medidas de erro confrontando as projeções feitas para as microrregiões mineiras de 2010 com a realidade observada no Censo Demográfico do mesmo ano. Os resultados mostram que técnicas simples de projeção são aderentes à realidade no curto prazo. Aponta-se que as dissonâncias presentes entre as projeções e a realidade observada devem-se aos efeitos dimensionais, temporais e espaciais que as técnicas não conseguem mensurar com exatidão, mas que não invalidam seu uso a partir do conhecimento de suas limitações.
\end{abstract}

Palavras-chave: Projeções populacionais. Pequenas áreas. Técnicas demográficas. Minas Gerais.

\footnotetext{
* Centro de Desenvolvimento e Planejamento Regional - Cedeplar, Universidade Federal de Minas Gerais - UFMG, Belo Horizonte-MG, Brasil (reinaldoos@cedeplar.ufmg.br).

${ }^{\star \star}$ Centro de Desenvolvimento e Planejamento Regional - Cedeplar, Universidade Federal de Minas Gerais - UFMG, Belo Horizonte-MG, Brasil (barbieri@cedeplar.ufmg.br).
} 


\section{Introdução}

Os estudos populacionais abarcam uma série de campos de conhecimento fragmentados pelo modo de se fazer ciência na modernidade, mas unidos pelo objeto em questão, ou seja, a população. Os cientistas que se ocupam do planejamento territorial, em especial o geógrafo, o demógrafo, o economista, o sociólogo e o arquiteto urbanista, para citar alguns exemplos, chegam a uma etapa de suas investigações em que a demanda por projeções populacionais é uma importante necessidade de pesquisa.

Numa tentativa de entender o papel dos estudos sobre população no planejamento do desenvolvimento, foi realizado, em 1989, o Simpósio sobre População e Planejamento para o Desenvolvimento, em Riga, na Letônia (UNITED NATIONS, 1993). Uma das recomendações do documento final foi a de inserção de variáveis demográficas no processo de planejamento, tendo em vista que, para se ter uma visibilidade maior sobre o futuro, é necessária a construção de projeções tanto do capital quanto da força de trabalho (UNITED NATIONS, 1993).

Segundo Rees (1993), projeções populacionais são elementos-chave no planejamento para o desenvolvimento, sendo determinantes para a construção de políticas públicas. No Brasil, ${ }^{1}$ alguns estudos têm se dedicado a este esforço, contribuindo com criação, aplicações e adaptações de técnicas de projeções para pequenas áreas (WALDVOGEL, 1998; BRITO; CAVENAGHI; JANNUZZI, 2010; JANNUZZI, 2007; FÍGOLI et al., 2010; GOMES, 2010; GONZÁLEZ; TORRES, 2012). Estes trabalhos fazem parte de um esforço contínuo dos estudiosos sobre população para avaliar as técnicas correntemente empregadas, fazendo coro com a literatura internacional sobre a aplicabilidade no processo de planejamento para 0 desenvolvimento, em especial daqueles com forte base territorial.

Nesse sentido, com o fito de contribuir com tais estudos, o presente artigo aborda cinco técnicas de projeções para pequenas áreas - extrapolação linear e exponencial, partição constante, shift-share e $\mathrm{AiBi}$-, aplicando as mesmas às microrregiões de Minas Gerais para o ano de 2010. A escolha dessas técnicas deve-se à facilidade de aplicação e replicação das mesmas, bem como ao seu uso frequente, por parte dos responsáveis por diagnósticos, para elaboração de planos. Quanto ao horizonte de projeção, uma vantagem imediata é a possibilidade de utilizar os dados censitários de 2010 para avaliação da aderência em relação aos dados observados. ${ }^{2}$ Para tanto, são apresentadas algumas medidas de erro, apontando as limitações das técnicas empregadas.

\footnotetext{
${ }_{1}^{1}$ Para um maior conhecimento da agenda recente de trabalhos sobre aplicações de técnicas de projeção na América Latina, ver Cavenaghi (2012).

2 Uma alternativa seria construir um modelo de projeção com variáveis sintomáticas, além do uso da tendência, e avaliar a qualidade do modelo por meio da significância estatística das covariáveis dentro do período base (1991 a 2000). Contudo, como será visto a seguir, esse trabalho irá comparar técnicas que levam em consideração a tendência, sem levantar variáveis sintomáticas e, por isso, torna-se possível validar as técnicas somente em comparação com a população observada fora do período base. Outro ponto sensível é o fato de existirem problemas de cobertura no processo de coleta de dados que implicam a geração de desvios entre a população registrada/observada no censo e a população real.
} 
Também chamados de pequenos domínios, as pequenas áreas aqui descritas não possuem limites definidos na literatura. Em geral, referem-se a unidades de planejamento que podem variar entre setores censitários e unidades de planejamento subnacionais que ultrapassam limites políticos. Segundo Smith e Morrison (2005, p. 3), pequenas áreas "vary in size from less than an acre to thousands of square miles, and from a mere handful of residents (or none at all) to many millions". No presente artigo, pequena área define-se como unidade territorial na qual o número de habitantes é insuficiente para garantir resultados satisfatórios por métodos como o das componentes demográficas, mas que necessitam ser modeladas conjuntamente para a construção da condição de retorno, ou seja, a de que o crescimento do conjunto territorial maior seja resultante da soma das unidades menores.

A escolha de Minas Gerais deve-se à sua diversidade regional e à influência socioeconômica exercida por outras Unidades da Federação e o Distrito Federal sobre as suas microrregiões. Essa característica heterogênea do Estado contribui para a emergência de idiossincrasias que se refletem no crescimento demográfico (BARBIERI; SANTOS, 2011; MATOS; GARCIA, 2006; GIOVANINI, 2006). A determinação das microrregiões geográficas como pequenas áreas deve-se a dois motivos: facilita a comparação entre períodos distintos, uma vez que o processo de emancipação municipal ocorrido intensamente nos anos 1990 não afetou a conformidade da regionalização; e pelo fato de a maior parte destas unidades não possuir tamanho populacional suficiente para garantir a estabilidade necessária para a projeção pelos métodos tradicionais. Espera-se que o artigo sirva de referência para aqueles que estão iniciando seus estudos no tema, além de instrumento para pesquisadores que se ocupam da análise regional em suas investigações. ${ }^{3}$

\section{Projeções demográficas}

Uma das importantes contribuições da demografia é o desenvolvimento de técnicas para estudar o crescimento e a distribuição populacional a partir da dinâmica de suas componentes: fecundidade, mortalidade e migração. Tais componentes são determinadas pela composição da população por idade e sexo, definindo as frações da população que participam do crescimento por meio da fecundidade, população em risco de morte e com maior ou menor propensão a migrar. Ainda assim, variações nessas componentes respondem a elementos vários - econômicos e não econômicos -, que sofrem alterações no tempo e no espaço (PRESTON et al., 2001; SMITH, 1984).

O demógrafo, entre outros aspectos, ocupa-se de compreender essa dinâmica que define a população e, talvez por isso, uma das demandas levadas a este profissional é a elaboração de projeções futuras sobre o contingente populacional. 0 setor público, por exemplo, necessita saber qual será a população que dependerá de seus serviços, não apenas em

\footnotetext{
${ }^{3}$ Entende-se que a discussão sobre projeções de populações abertas exige um trabalho exclusivo. A respeito da discussão entre fatores exógenos sobre a instabilidade das componentes demográficas, bem como dos desafios de modelagem e simulação, ver United Nations (1974, 1989), Isnard (1960) e Rogers (1985).
} 
sua totalidade, mas também em grupos específicos. É nesse sentido que surgem perguntas como: quantos idosos dependerão de determinados serviços de saúde? Quantas crianças demandarão por mais ou menos recursos na educação básica? Qual é o investimento em infraestrutura básica que deverá ser despendido e onde? Quantos seremos no futuro? Como estaremos distribuídos espacialmente? 0 mercado, por seu turno, demanda conhecimento de seus segmentos específicos, perfil de consumidores, suas preferências e sua localização. Assim, o demógrafo pretende responder a algumas questões essencialmente geográficas, a saber: quantos serão os indivíduos de uma determinada área; como essa população estará distribuída no espaço; e quais suas consequências para a sociedade.

Todavia, o que são projeções populacionais? Para Rogers (1985), trata-se de valores numéricos da população futura obtidos, geralmente, por extrapolação do passado e tendências correntes. Para Smith et al. (2001), Smith (1984) e Stoto (1983), projeções são resultados numéricos de um conjunto particular de pressupostos sobre as tendências futuras do crescimento populacional. De fato, qualquer projeção populacional é dependente de pressupostos, tanto no momento da escolha de determinado período e seleção da população base quanto como considerá-la indicador das tendências futuras. ${ }^{4}$

Keyfitz (1981) afirma que o ato de projetar é como acertar um objeto em movimento errático. Assim, "acertar" o alvo requer habilidade técnica e sofisticação, mas também depende de sorte. Determinar com máxima precisão a dimensão populacional exige também que a população não seja instável ${ }^{5}$ no horizonte de projeção, diminuindo o erro. Stoto (1983), por exemplo, ao analisar as projeções estadunidenses no início da década de 1980, indicava a redução dos erros, atribuindo como causa a melhoria das técnicas empregadas e a maior estabilidade da população. Keyfitz (1981) e Stoto (1983) apontam como indicador de erro a diferença entre a população projetada e aquela observada no período projetado. Segundo os autores, os erros tendem a aumentar quando o horizonte temporal é maior e/ou a população tem dimensão cada vez menor.

Entrementes, projeções populacionais nem sempre têm o objetivo de predizer o futuro, pois muitas vezes, para analistas de mercado e agentes públicos de decisão, o interesse maior é na construção de cenários a partir de alguns eventos ou investimentos que se pretende realizar em determinada região (SMITH et al., 2001). Para isso, bastaria alterar os pressupostos e inserir as variáveis que determinariam a alteração no padrão de crescimento populacional e, a partir daí, construir cenários demográficos alternativos. Previsão ${ }^{6}$ seria

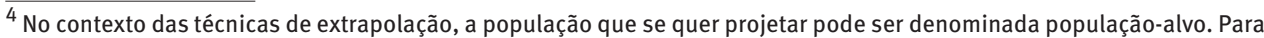
a projeção, podem-se utilizar duas referências temporais, uma mais recente que servira de ponto de partida (população inicial) e uma mais antiga (população base) que, em comparação com a população inicial, fornecerá informações sobre o comportamento do crescimento dentro de um período que se denominará período base (diferença entre o ano base e o ano inicial de projeção).

${ }^{5}$ Entende-se como “instabilidade" variações no crescimento populacional que dificultam a predição. Como será descrito ao longo do artigo, a instabilidade é maior em situações de grande crescimento populacional ou populações de pequenas dimensões, situações em que oscilações econômicas e ambientais de curto prazo dificultam a predição. Efeitos de correlação espacial e o tamanho do horizonte de projeção também afetam negativamente a precisão das projeções essencialmente tendenciais, caracterizando um desafio técnico de estimação.

${ }^{6}$ Do inglês forecasting. Em português usam-se, indistintamente, os dois termos como projeções.
} 
o termo mais adequado para as projeções em que o pesquisador pretende construir um cenário provável para a população no futuro. Para as previsões é possível elaborar um teste de veracidade, ao passo que as projeções que buscam desenhar cenários alternativos só podem ser confrontadas com a realidade se seus pressupostos se realizarem. Vale ressaltar que toda previsão é uma projeção, mas nem toda projeção é uma previsão propriamente dita.

Quando há falta de dados correntes ou passados sobre determinada população, é comum o uso de técnicas de projeção para estimar seu contingente. Não se trata de uma previsão propriamente dita, pois a população de fato já está (ou foi) inscrita na realidade. Para essas projeções, usa-se a denominação de estimativa (SMITH et al., 2001).

Quanto aos tipos de métodos de projeção populacional, destacam-se aqueles denominados subjetivos, ou qualitativos, e os objetivos, ou quantitativos. Os métodos qualitativos obtêm seus pressupostos na construção do cenário futuro a partir de opiniões de especialistas quanto ao comportamento das componentes demográficas ou do contingente populacional em grupos e em sua totalidade. Em geral, eles baseiam-se em impressões, intuições e tendências passadas, sendo necessários quando não há informações suficientes. Contudo, esses métodos têm a dificuldade de replicação por seu caráter não quantitativo, ao contrário dos pressupostos matemáticos (SMITH et al., 2001).

Entre esses métodos qualitativos, podem ser elencados os judgemental scenarios, que buscam a confluência dos julgamentos de especialistas sobre aspectos de algumas variáveis ou componentes demográficas. Segundo Bijak (2006), esse método é muito utilizado na construção de cenários, indicando tendências e simulações de alternativas no curso tendencial. Na verdade, a construção de pressupostos em técnicas objetivas passa por esse método, com o aporte técnico e experiência de especialistas na construção de cenários futuros, prováveis ou alternativos, das componentes demográficas.

Outro método qualitativo de projeção é o de survey entre especialistas, conhecido como método Delphi. Trata-se da elaboração de questionários aplicados em várias rodadas com o maior número possível de especialistas. As perguntas aos especialistas são orientadas para apontar quais são os principais balizadores e o comportamento das variáveis que determinam o crescimento populacional. 0 resultado é um agregado de informações que foram adquiridas por iteração, sendo que as opiniões individuais são sobrepostas até obter-se um consenso sobre os pressupostos a serem aplicados (WRIGHT; GIOVINAZZO, 2000; BIJAK, 2006; JANNUZZI, 2006).

Os métodos objetivos ou quantitativos, por seu turno, são aqueles nos quais o cenário futuro é construído a partir de modelos matemáticos e, por isso, são de mais fácil replicação para se obterem resultados comparáveis. Smith et al. (2001) e Smith (1984) classificam essas técnicas em três grupos, a saber: extrapolação matemática, componentes demográficas e modelos estruturais. As seções subsequentes apresentarão essas técnicas com uma breve descrição, sobretudo sobre seus usos para projeções de pequenas áreas. Os ratio methods são descritos em uma seção à parte das técnicas de extrapolação matemática por configurarem um caso especial de extrapolação, em que é respeitada, sem necessidade 
de ajuste, a condição de retorno, ou seja, a soma das subpopulações projetadas é igual ao total populacional.

\section{Métodos de projeção}

\section{Extrapolação matemática}

Os modelos de extrapolação matemática baseiam-se em informações no tempo para predizer o futuro da população (SMITH et al., 2001). Seu objetivo é determinar uma função que se ajuste ao comportamento do crescimento populacional ao longo do tempo (WALDVOGEL, 1998). Uma limitação desses métodos é sua decomposição, uma vez que a extrapolação em separado de frações da população não será igual à extrapolação do todo. Waldvogel (1998) aponta que a extrapolação é um problema maior quando se trata de pequenas populações ou pequenas áreas.

Nesse sentido, Whitte e Siegel (apud WALDVOGEL, 1998) propuseram a extrapolação da participação das pequenas áreas em relação à área maior para satisfazer a condição de retorno, ou seja, a soma das partes é igual ao todo. Esse método ficou conhecido como Census Bureau Ratio. Mesmo assim, em situações de crescimento ou decrescimento rápido da população, pode-se chegar a informações pouco verossímeis sobre a participação das populações menores (WALDVOGEL, 1998).

\section{Métodos estruturais}

Os métodos estruturais são aqueles que produzem projeções a partir do uso de variáveis independentes, econômicas e não econômicas (SMITH et al., 2001). Isso faz com que tais modelos sejam bastante úteis para a gestão e planejamento urbano e regional, servindo para avaliar impactos de empreendimentos de infraestrutura que alterem de alguma forma as componentes demográficas.

Em geral, o foco dos modelos estruturais é a componente migração, por ser esta mais sensível a mudanças econômicas, sociais e ambientais (SMITH et al., 2001). De fato, nos modelos denominados econômico-demográficos, em que se estimam a variação do salário real no espaço ou ainda mudanças na estrutura produtiva regional e do nível de empregabilidade, a migração apresentará uma resposta mais imediata, ao passo que fecundidade e mortalidade responderão mais lentamente.

Os métodos dos sistemas urbanos diferem dos econômico-demográficos por duas características apenas. Primeiramente, os métodos dos sistemas urbanos podem operar com maior precisão espacial, ou seja, em áreas menores ou escalas cartográficas maiores. ${ }^{7}$ Esses modelos abarcam também um número maior e mais diversificado de variáveis, incluindo informações habitacionais e de transporte, o que possibilita varia-

\footnotetext{
${ }^{7}$ Sobre precisão e o uso da escala como categoria de análise, ver Gibson e Ostrom (2000), Vainer (2002), Castro (2002) e Barbieri (2007).
} 
ções de modelos gravitacionais e mobilidade a curtas distâncias (SMITH et al., 2001). Em função da existência de uma variedade de técnicas inseridas nesse grupo, a forma de validação das projeções possui diferentes medidas de erro, variando entre as mais convencionais que avaliam o estoque (erro médio, valor quadrático, entre outros) até variações provenientes de álgebra de mapas. Essa discussão, que mereceria um trabalho à parte, não será aprofundada aqui.

0 modelo de projeção utilizado por Santos (2010) e Barbieri e Santos (2011), para a região do Alto Paraopeba, inclui-se na categoria econômico-demográfica, não a partir da predição da migração, mas sim da população em sua totalidade segundo a variação do nível de emprego. A opção pelo conjunto populacional vem do problema da pequena dimensão dos municípios, ou mesmo da região, para estimar a migração, o que gera grande instabilidade. No entanto, se a população cresce devido ao aumento do nível de emprego, isso se dá, predominantemente, como resultado dos efeitos diretos e indiretos da migração.

\section{Método das componentes demográficas}

O método mais utilizado para projeção populacional tendencial de grandes populações (mais estáveis) é o dos componentes de coorte, que observa analiticamente a dinâmica das componentes demográficas em separado para, a posteriori, determinar o crescimento da população (CELADE, 1984). A vantagem desse método consiste em incluir uma maior variedade de conhecimentos específicos sobre a evolução das componentes demográficas. De fato, demógrafos tendem a se especializar em alguma componente demográfica e, com isso, a contribuição de especialistas na determinação de hipóteses sobre tais variáveis auxilia na construção de uma projeção mais verossímil (O’NEIL et al., 2001).

0 método das componentes, como comumente denominado, tem suas origens na equação de balanceamento, tão cara à Demografia por expressar seu objeto de estudo na conjugação das componentes demográficas (ATCHLEY, 1970; IPARDES, 1999; IBGE, 2008). Assim, tem-se:

$P_{t+n}=P_{l}+N_{t, t+n}-M_{t, t+n}+I_{t, t+n}-E_{t, t+n}$

0 índice $t$ representa a primeira referência temporal, $n$ indica o intervalo ou período base e $t+n$ refere-se ao final do período. A variável $P$ corresponde ao total da população, $N$ é o número de nascimentos ocorridos entre $t$ e $t+n, M$ representa o número de óbitos ocorridos no mesmo período, $I$ e $E$ denotam a variação no estoque populacional decorrente da imigração e da emigração entre $t$ e $t+n$. Logo, a população de determinado momento $t+n$ é definida pela dimensão da população inicial, com o acréscimo dos nascimentos e dos imigrantes no período $t$ a $t+n$, bem como subtraídos os óbitos e os emigrantes no mesmo intervalo.

Esse método é aplicado a uma unidade espacial maior para balizar projeções de pequenas áreas, dentro de modelos relacionais que serão apresentados a seguir. Entretanto, 
quanto menor for a população, maior é a instabilidade das componentes e dos grupos por idade e sexo necessários para a projeção, distanciando os resultados da realidade ou do cenário a ser construído.

\section{Ratio methods}

Os modelos denominados ratio methods (ou métodos de razão) fazem parte, entre os métodos objetivos de projeção, de uma forma específica de extrapolação matemática. Nesse método, as populações das áreas menores são determinadas como frações da área maior à qual elas pertencem (UNITED NATIONS, 1956; SMITH et al., 2001). Nesse sentido, os ratio methods são técnicas de projeções de pequenas áreas de cunho distributivo e que possuem a vantagem inerente de automaticamente respeitarem a condição de retorno, sem a necessidade de ajuste, ou seja, a soma das populações das áreas menores é igual à projeção da população da área maior. Outros métodos de projeção, em geral, demandam algum tipo de padronização, corrigindo o nível de projeção segundo o erro de estimativas entre a área maior e a soma das áreas menores.

0 uso de relações ou razões pode ser feito de forma mais sofisticada, estimando o crescimento da população menor por grupos de idade e sexo (JARDIM, 2000). 0 método de relação de coortes é concebido a partir do pressuposto de que, num período base, o crescimento de uma coorte ou grupo populacional de uma área menor relaciona-se linearmente com o mesmo grupo ou coorte na área maior à qual faz parte (JARDIM, 2000; DUCHESNE, 1987; SWANSON; SCHLOTTMANN; SCHMIDT, 2010; BRITO; CAVENAGHI; JANNUZZI, 2010). A limitação da relação de coortes como técnica é o seu uso em grupos populacionais muito pequenos, que, por sua dimensão, apresentam grande instabilidade e informações insuficientes por idade e sexo.

Outra forma de projetar a população por idade e sexo é o emprego da correlação de coortes (DUCHESNE, 1987; JARDIM, 2000; BRITO; CAVENAGHI; JANNUZZI, 2010). Essa técnica estabelece que a relação de coortes de uma população é determinada por um conjunto de relações de crescimento entre a área menor e a área maior de variáveis sintomáticas. Assim, ajusta-se um modelo de regressão múltipla tendo como variável resposta a relação intercensitária entre as populações dos dois níveis constitutivos e, como variáveis independentes, relações entre as variáveis sintomáticas nas duas escalas. Esses indicadores podem ser econômicos ou não econômicos, tais como nascidos vivos, óbitos, número de eleitores, emprego, número de matrículas, entre outros (JARDIM, 2000). Tal como o método de relação de coortes, populações muito pequenas em que os grupos etários são instáveis são difíceis de predizer, limitando o uso da técnica.

Entre os ratio methods, a partição constante considera que a população da área menor tem sua participação no conjunto da área maior constante ao longo do tempo, bem como a população a ser projetada terá seu crescimento determinado pela participação da população pretérita na população total (SMITH et al., 2001). A partição constante, nesse sentido, 
demanda informações históricas de apenas um ponto no tempo, apesar de ser muito importante a avaliação de outras referências temporais para se ter uma ideia mais precisa dessa tendência de crescimento. 0 método é descrito formalmente da seguinte maneira: $P_{i t}=\left(P_{i l} / P_{j l}\right) P_{j t}$

Onde $P_{i t}$ é a população da área menor a ser projetada, $P_{i l}$ e $P_{j l}$ são, respectivamente, as populações das áreas menor e maior no início da projeção e $P_{j t}$ corresponde à população da área maior no ano a ser projetado.

Essa técnica é interessante quando o tamanho da população torna-se uma boa proxy para fatores positivos da estrutura de oportunidades econômicas regionais, da acessibilidade ao mercado imobiliário, de ativos públicos e privados disponíveis, estrutura viária e de comunicação que facilite os fluxos materiais e imateriais, enfim, condições que determinam o crescimento da população diante de situações de crescimento condicionado pela mobilidade populacional. Todavia, essa técnica de projeção considera que a área menor crescerá exatamente à mesma taxa que a área maior, o que em geral não é um pressuposto razoável, salvo situações de choques exógenos no crescimento demográfico.

Outra técnica muito utilizada é conhecida como shift-share, que, ao contrário da partição constante, considera que a participação das localidades no conjunto da população total altera-se com o tempo (SMITH et al., 2001). Nesse sentido, a técnica mede a mudança na participação das pequenas áreas dentro do período base, ou seja, entre o ano base e o ano inicial de projeção, multiplicando-o por um fator que indica o horizonte de projeção. Com a construção desse indicador de mudança na participação, agrega-se a distribuição inicial da projeção e, novamente, multiplica-se pela projeção da área maior. Em termos algébricos, o método pode ser expresso da seguinte forma:

$P_{i t}=P_{j t}\left[P_{i l} / P_{j l}+(z / y)\left(P_{i l} / P_{j l}-P_{i b} / P_{j b}\right)\right]$

Onde $z$ é o horizonte de projeção e $y$ é o período base. $P$ indica a população e os índices $i$ e $j$ correspondem, respectivamente, às áreas menor e maior. Os índices $t, b$ e $l$ referem-se, respectivamente, ao ano a ser projetado, ao ano base e ao ano inicial de projeção.

Apesar da vantagem em termos de maior sensibilidade a mudanças estruturais e espaciais da população na área maior, essa técnica pode levar a uma estimava de população que tem variações negativas de participação e a valores iguais ou menores que zero. Assim, ajustes podem ser feitos utilizando métodos conjugados de extrapolação linear ou opiniões de especialistas sobre as perspectivas futuras de crescimento nas pequenas localidades.

Por fim, a técnica denominada apportionment method, ou projeção da participação no crescimento, consiste em projetar a população da pequena área com base na sua contribuição no crescimento absoluto da população esperada na área maior (UNITED NATIONS, 1956; WALDVOGEL, 1998; BARBIERI et al., 2010; SZWARCWALD; CASTILHO, 1989). No Brasil, este método é conhecido como método dos coeficientes ou simplesmente AiBi e foi utilizado primeiramente por Madeira e Simões (1972) para projetar os contingentes rural e urbano entre 1960 e 1980, segundo as Unidades da Federação. 
Ao contrário das técnicas de extrapolação matemática e métodos estruturais, a partição do crescimento considera que o crescimento das áreas menores possui relação linear com o crescimento da área maior (SMITH et al., 2001). Assim, pode-se escrever da seguinte forma: $P_{i t}=P_{i l}+\left[\left(P_{i l}-P_{i b}\right) /\left(P_{j l}-P_{j b}\right)\right]\left(P_{j t}-P_{j l}\right)$

Onde $P$ é a população, $i$ corresponde ao índice da área menor, $j$ representa a área maior, $P t$ é a população a ser projetada, $P b$ refere-se à população base e $P l$ é a população inicial de projeção. Outra maneira de descrever essa equação seria:

$P_{i t}=A_{i} P_{j t}+B_{i}$

Onde $A i$ é um coeficiente de proporcionalidade entre o crescimento da área menor e da área maior e Bi representa um coeficiente linear de correção (WALDVOGEL, 1998). Em termos algébricos, temos:

$A_{i}=\left(P_{i l}-P_{i b}\right) /\left(P_{j l}-P_{j b}\right)$

$B_{i}=P_{i l}-A_{i} P_{j l}$

Uma vantagem de usar a equação (5) é a interpretação de seus valores e a possibilidade de ajuste. A exposição dos coeficientes e seus resultados para um grupo de especialistas pode contribuir para o ajuste de valores mais adequados para os parâmetros $A i$ e $B i$, conjugando a esta técnica outras que chamamos anteriormente de subjetivas. Pode-se também, como anteriormente proposto para o shift-share, usar algum método de extrapolação, linear ou não, para aqueles municípios que tendem a apresentar ao longo do horizonte de projeção valores iguais ou menores que zero. Para evitar resultados improváveis, comumente divide-se essa partição do crescimento entre as unidades que possuem crescimento positivo e aquelas que apresentam crescimento negativo, ou mesmo agrupando conjuntos populacionais com taxas de crescimento e tamanho populacional similares (WALDVOGEL, 1998; FíGOLI et al., 2010).

\section{A escolha da técnica de projeção}

A elaboração da projeção sempre envolve a tentativa de reduzir os erros em relação à realidade ou ao cenário que se tenta predizer. Mesmo numa situação de construção de cenários alternativos, busca-se avaliar o real efeito de uma série de fatores sobre o crescimento populacional e, para tanto, o processo de estimação deve ser o mais sensível possível às verdadeiras relações entre as variáveis. Nesse sentido, em muito seria útil se existisse uma técnica de projeção universal que se adequasse a diferentes realidades.

Um dos balizadores para a escolha da técnica a ser empregada é a definição do horizonte de projeção. Algumas técnicas podem contribuir para a confluência com a realidade em horizontes maiores de projeção, outras em intervalos menores (KEYFITZ, 1981). Outro item relevante à escolha da técnica é a adequação às características do espaço a ser projetado, uma vez que nele estão inseridos os principais condicionantes, econômicos ou não, do crescimento populacional. 
Além de dar atenção à estrutura socioespacial, a conjuntura na qual a população está inserida também determina as condições futuras de suas componentes. A migração, por exemplo, responde mais rapidamente a fatores conjunturais, gerando maior impacto no crescimento demográfico quanto menor for a dimensão da população.

Estrutura e conjuntura socioespaciais são importantes elementos de decisão de como projetar a população, mas devem vir em consonância com o objetivo do trabalho. Se a população será considerada fator exógeno ao processo estudado, projeções tendenciais podem atender à demanda. Por outro lado, se a população é endógena, então é necessário um conjunto de dados para criar um modelo estrutural que forneça informações sobre o impacto das variáveis relacionadas ao crescimento populacional.

Propõe-se, na próxima seção, um exercício de projeção populacional para Minas Gerais e suas microrregiões. Será executado o procedimento comumente utilizado quando se conjugam projeções em dois níveis, à grande e às pequenas áreas. A projeção populacional elaborada pelo IBGE para 2010 (IBGE, 2008), para o Estado de Minas Gerais, foi considerada como grande área.

As projeções de pequenas áreas utilizam as informações de Minas Gerais e de suas microrregiões geográficas para 1991 e 2000. Após aplicar as técnicas AiBi, shift-share, partição constante, extrapolação linear e extrapolação exponencial para a projeção das microrregiões para o ano de 2010, os resultados são confrontados com as informações disponíveis no Censo 2010 a partir de algumas medidas de erro. Conceitualmente, empregar as técnicas de repartição para determinar a população das pequenas áreas junto aos dados de último censo seria produzir estimativas e não projeções (forecasting). Nesse sentido, optou-se por lançar mão de duas projeções paralelas por se tratar do caminho usual quando não se dispõem de informações sobre a população no ano de projeção.

\section{Aplicação de técnicas de projeção: microrregiões de Minas Gerais}

Como dito anteriormente, as microrregiões geográficas de Minas Gerais possuem diversas assimetrias econômicas, geográficas, sociais e populacionais. Sobre esse último aspecto, a microrregião onde se insere a capital Belo Horizonte acaba por guardar também a primazia populacional do Estado. Em contraponto, 11 microrregiões possuem menos de 100 mil habitantes. Destaque deve ser dado para Grão-Mogol, microrregião com menos de 50 mil habitantes (Gráfico 1).

Como apontado no Gráfico 1, a avaliação por quartos de população mostra, além da primazia, uma maior variabilidade dentro do 4 우 quartil. De fato, como também indica a Tabela 1, Belo Horizonte constitui-se como outlier, com 4.772 .562 habitantes, 5,82 vezes maior do que a segunda microrregião (Uberlândia, com 820.245 habitantes). 
GRÁFICO 1

Tamanho populacional médio e coeficiente de variação das microrregiões geográficas (quartos de população)

Estado de Minas Gerais - 2010

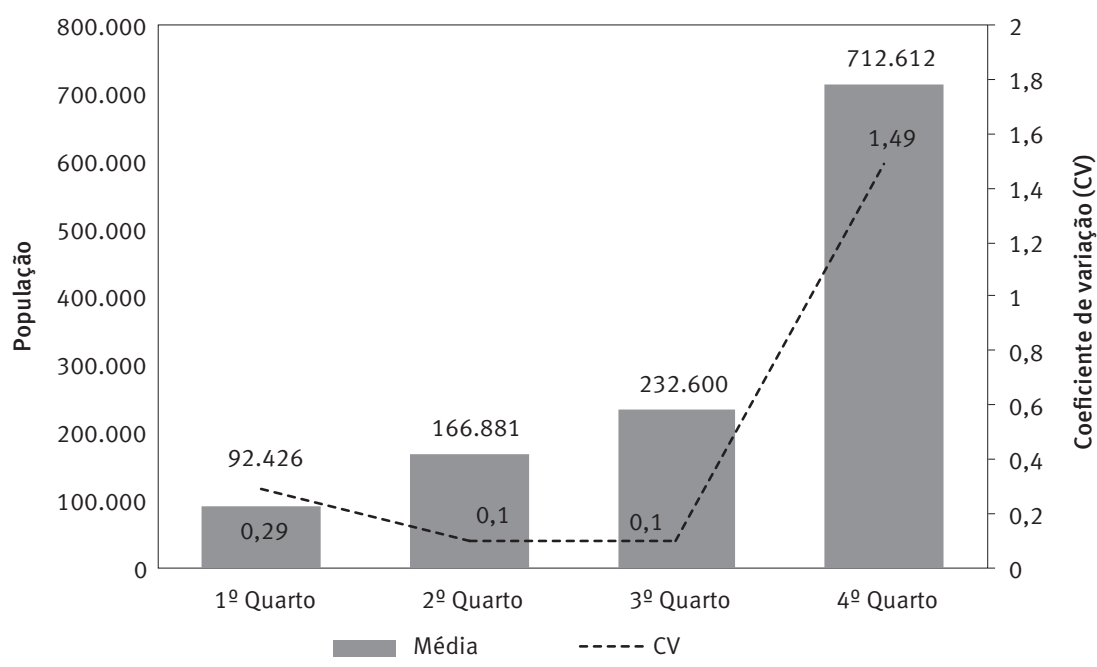

Fonte: IBGE. Censo Demográfico de 2010.

A seguir, são apresentados os resultados de projeções elaboradas a partir dos dados de 1991 e 2000, bem como a projeção feita pelo IBGE para 2010 (IBGE, 2008) (Tabela 1). Os ratio methods utilizados demandaram apenas a projeção do IBGE e as informações censitárias para cada microrregião em 1991 e 2000. A dificuldade das técnicas de extrapolação linear e exponencial em atenderem a condição de retorno foi resolvida utilizando um fator de correção, a saber, a relação entre a soma das projeções das microrregiões e a projeção do IBGE para $2010 .{ }^{8}$ A escolha das microrregiões como unidade de projeção teve o objetivo de evitar problemas de reconstituição de municípios devido ao processo de emancipação ocorrida, em grande parte, na década de 1990. Quando emancipados, os novos municípios permanecem nas microrregiões dos municípios de origem, o que garante a comparabilidade temporal. ${ }^{9}$

\section{Medidas de erro para projeções}

Nas situações em que as projeções focam no cenário provável, é possível utilizar algumas medidas de erro para aferir a qualidade das estimativas como, por exemplo, analisando a diferença entre a população observada e a projetada (STOTO, 1983). Keyfitz (1981) indica que o valor quadrático médio ${ }^{10}$ dos erros (root mean square error) é mais útil para a avaliação, uma vez que salienta os erros maiores e reduz a importância dos

\footnotetext{
8 Para a extrapolação linear o fator determinado foi de 0,997, enquanto para a extrapolação exponencial foi de 0,971.

${ }^{9}$ A projeção em foco trata-se de um exercício que, na escala utilizada, é útil para a visão de unidades de planejamento supramunicipais. Os mesmos métodos podem ser utilizados na escala municipal ou intramunicipal, incluindo possibilidades de repartição em dois níveis ou mais níveis com o uso de variáveis sintomáticas ou de tendência para atender à demanda de políticas públicas.

${ }^{10}$ Raiz quadrada da média dos quadrados dos erros absolutos (diferença entre população projetada e observada).
} 
pequenos erros. Smith e Shahidullah (1995) utilizam, para a comparação de metodologias de projeção de pequenas áreas, o erro médio, ou seja, o desvio médio entre a população observada e a projetada para o conjunto das pequenas áreas. Waldvogel (1998) coloca como alternativa uma medida de erro relativo que consiste na soma em módulo das diferenças entre a população projetada e a observada, ambas divididas por essa última. Quando as projeções da grande área e das pequenas áreas são feitas de forma independente, pode-se estimar, num primeiro momento, o erro decorrente dessa diferença. Para tanto, somam-se as populações das áreas menores e o resultado é dividido pela projeção da área maior (WALDVOGEL, 1998). Assim, obtém-se um fator de correção para a soma das projeções das pequenas áreas que é igual ao da grande área, como foi utilizado para Minas Gerais e suas microrregiões.

TABELA 1

População observada e projetada por diferentes técnicas de projeção, segundo microrregiões Estado de Minas Gerais - 1991-2010

\begin{tabular}{|c|c|c|c|c|c|c|c|c|}
\hline \multirow[b]{2}{*}{ Microrregiões } & \multicolumn{3}{|c|}{ População observada } & \multicolumn{5}{|c|}{ População projetada para 2010} \\
\hline & 1991 & 2000 & 2010 & $\mathrm{AiBi}$ & Shift-share & $\begin{array}{l}\text { Partição } \\
\text { constante }\end{array}$ & $\begin{array}{c}\text { Extrapolação } \\
\text { linear }\end{array}$ & $\begin{array}{l}\text { Extrapolação } \\
\text { exponencial }\end{array}$ \\
\hline $\begin{array}{l}\text { Estado de } \\
\text { Minas Gerais (1) }\end{array}$ & 15.743.152 & 17.891 .494 & 19.597 .330 & 20.207.839 & 20.207 .839 & 20.207.839 & 20.207 .839 & 20.207.839 \\
\hline Unaí & 126.817 & 137.634 & 148.800 & 149.297 & 147.310 & 155.453 & 149.131 & 146.741 \\
\hline Paracatu & 178.468 & 1.968 .75 & 217.618 & 216.721 & 214.900 & 222.364 & 216.570 & 213.739 \\
\hline Januária & 248.363 & 257.072 & 274.092 & 266.462 & 258.750 & 290.354 & 265.819 & 260.023 \\
\hline Janaúba & 212.451 & 238.178 & 247.487 & 265.917 & 264.917 & 269.014 & 265.833 & 263.261 \\
\hline Salinas & 184.439 & 199.803 & 210.771 & 216.368 & 213.366 & 225.671 & 216.118 & 212.588 \\
\hline Pirapora & 146.688 & 154.802 & 164.903 & 163.551 & 159.905 & 174.844 & 163.246 & 159.986 \\
\hline Montes Claros & 469.508 & 539.049 & 601.867 & 614.028 & 615.704 & 608.838 & 614.168 & 611.793 \\
\hline Grão Mogol & 39.323 & 40.679 & 42.669 & 42.141 & 40.913 & 45.946 & 42.039 & 41.120 \\
\hline Bocaiúva & 58.277 & 63.132 & 68.624 & 68.367 & 67.418 & 71.305 & 68.288 & 67.172 \\
\hline Diamantina & 81.509 & 81.828 & 82.707 & 82.172 & 78.864 & 92.422 & 81.896 & 80.004 \\
\hline Capelinha & 174.791 & 187.314 & 197.507 & 200.816 & 197.347 & 211.565 & 200.527 & 196.919 \\
\hline Araçuaí & 149.407 & 151.851 & 156.418 & 154.486 & 148.991 & 171.511 & 154.028 & 150.513 \\
\hline Pedra Azul & 83.200 & 85.247 & 83.123 & 87.454 & 84.604 & 96.284 & 87.216 & 85.258 \\
\hline Almenara & 169.331 & 172.632 & 179.658 & 176.191 & 170.126 & 194.982 & 175.685 & 171.698 \\
\hline Teófilo Otoni & 270.740 & 260.917 & 266.651 & 250.326 & 236.004 & 294.697 & 249.131 & 243.778 \\
\hline Nanuque & 124.248 & 119.818 & 118.762 & 115.042 & 108.493 & 135.330 & 114.495 & 112.029 \\
\hline Ituiutaba & 130.266 & 133.073 & 143.348 & 136.100 & 131.515 & 150.301 & 135.717 & 132.649 \\
\hline Uberlândia & 564.691 & 702.074 & 820.245 & 850.201 & 868.673 & 792.969 & 851.742 & 870.541 \\
\hline Patrocínio & 155.905 & 183.721 & 197.700 & 213.712 & 215.715 & 207.507 & 213.879 & 214.638 \\
\hline Patos de Minas & 199.527 & 232.444 & 253.241 & 267.935 & 269.677 & 262.538 & 268.081 & 268.120 \\
\hline Frutal & 144.634 & 154.208 & 179.512 & 164.531 & 161.418 & 174.173 & 164.271 & 161.199 \\
\hline Uberaba & 242.310 & 290.667 & 346.024 & 342.806 & 347.488 & 328.299 & 343.196 & 346.359 \\
\hline Araxá & 158.315 & 173.699 & 204.412 & 190.286 & 188.381 & 196.187 & 190.127 & 187.445 \\
\hline Três Marias & 78.789 & 88.628 & 96.839 & 99.236 & 98.957 & 100.102 & 99.213 & 98.329 \\
\hline Curvelo & 136.164 & 143.703 & 150.701 & 151.832 & 148.450 & 162.308 & 151.549 & 148.524 \\
\hline Bom Despacho & 133.362 & 148.661 & 165.172 & 165.156 & 164.268 & 167.908 & 165.082 & 163.278 \\
\hline
\end{tabular}


continuação

\begin{tabular}{|c|c|c|c|c|c|c|c|c|}
\hline \multirow[b]{2}{*}{ Microrregiões } & \multicolumn{3}{|c|}{ População observada } & \multicolumn{5}{|c|}{ População projetada para 2010} \\
\hline & 1991 & 2000 & 2010 & $A i B i$ & Shift-share & $\begin{array}{l}\text { Partição } \\
\text { constante }\end{array}$ & $\begin{array}{c}\text { Extrapolação } \\
\text { linear }\end{array}$ & $\begin{array}{l}\text { Extrapolação } \\
\text { exponencial }\end{array}$ \\
\hline Sete Lagoas & 286.428 & 347.113 & 393.875 & 412.544 & 419.158 & 392.052 & 413.095 & 418.336 \\
\hline $\begin{array}{l}\text { C. do Mato } \\
\text { Dentro }\end{array}$ & 88.159 & 88.326 & 84.605 & 88.506 & 84.873 & 99.761 & 88.203 & 86.164 \\
\hline Pará de Minas & 92.131 & 107.133 & 123.379 & 123.308 & 124.052 & 121.003 & 123.370 & 123.324 \\
\hline Belo Horizonte & 3.436 .060 & 4.259 .163 & 4.772 .562 & 5.146 .634 & 5.255 .103 & 4.810 .581 & 5.155 .684 & 5.263 .525 \\
\hline Itabira & 328.511 & 352.866 & 379.237 & 379.126 & 372.856 & 398.550 & 378.602 & 371.918 \\
\hline Itaguara & 56.366 & 58.089 & 61.411 & 59.947 & 58.119 & 65.610 & 59.794 & 58.472 \\
\hline Ouro Preto & 136.946 & 154.860 & 173.797 & 174.175 & 173.938 & 174.909 & 174.155 & 172.817 \\
\hline $\begin{array}{l}\text { Conselheiro } \\
\text { Lafaiete }\end{array}$ & 196.023 & 220.258 & 247.251 & 246.388 & 245.618 & 248.774 & 246.324 & 244.066 \\
\hline Guanhães & 128.492 & 128.178 & 130.963 & 127.839 & 122.374 & 144.773 & 127.383 & 124.440 \\
\hline Peçanha & 88.072 & 84.478 & 81.520 & 80.603 & 75.822 & 95.415 & 80.204 & 78.517 \\
\hline $\begin{array}{l}\text { Governador } \\
\text { Valadares }\end{array}$ & 382.507 & 397.060 & 415.696 & 1 & 401.223 & 448.466 & 411.789 & 402.903 \\
\hline Mantena & 65.812 & 61.870 & 63.208 & 57.620 & 53.662 & 69.880 & 57.290 & 56.234 \\
\hline Ipatinga & 410.334 & 473.962 & 526.781 & 542.566 & 544.903 & 535.324 & 542.761 & 541.542 \\
\hline Caratinga & 231.498 & 240.478 & 253.421 & 250.160 & 243.236 & 271.612 & 249.583 & 244.212 \\
\hline Aimorés & 154.689 & 148.242 & 149.404 & 141.291 & 132.852 & 167.434 & 140.587 & 137.643 \\
\hline Pium-í & 73.096 & 77.248 & 81.643 & 81.725 & 79.942 & 87.249 & 81.576 & 79.960 \\
\hline Divinópolis & 313.674 & 391.895 & 483.473 & 476.233 & 487.078 & 442.632 & 477.138 & 488.574 \\
\hline Formiga & 134.127 & 144.977 & 152.171 & 156.675 & 154.393 & 163.747 & 156.485 & 153.873 \\
\hline Campo Belo & 95.913 & 105.536 & 111.762 & 115.912 & 114.850 & 119.199 & 115.823 & 114.252 \\
\hline Oliveira & 109.249 & 119.448 & 125.981 & 130.445 & 129.002 & 134.912 & 130.324 & 128.402 \\
\hline Passos & 185.533 & 210.243 & 226.412 & 236.885 & 236.699 & 237.462 & 236.870 & 235.170 \\
\hline $\begin{array}{l}\text { S. Sebastião do } \\
\text { Paraíso }\end{array}$ & 221.567 & 253 & 77 & 3 & 33 & 98 & 61 & 31 \\
\hline Alfenas & 179.366 & 208.717 & 225.356 & 240.363 & 241.856 & 235.739 & 240.488 & 240.445 \\
\hline Varginha & 352.657 & 406.850 & 441.060 & 465.281 & 467.139 & 459.523 & 465.436 & 464.238 \\
\hline Poços de Caldas & 272.771 & 310.428 & 342.055 & 351.030 & 351.163 & 350.618 & 351.041 & 348.891 \\
\hline Pouso Alegre & 228.986 & 281.562 & 326.425 & 338.250 & 344.781 & 318.015 & 338.794 & 344.857 \\
\hline $\begin{array}{l}\text { Santa Rita do } \\
\text { Sapucaí }\end{array}$ & 113.804 & 128.212 & 0.170 & 3.747 & 143.403 & 144.811 & 143.718 & 142.488 \\
\hline São Lourenço & 171.609 & 195.821 & 208.293 & 221.926 & 222.170 & 221.173 & 221.947 & 220.736 \\
\hline Andrelândia & 70.783 & 73.571 & 73.870 & 76.577 & 74.473 & 83.096 & 76.401 & 74.761 \\
\hline Itajubá & 164.325 & 181.470 & 189.193 & 199.956 & 198.339 & 204.964 & 199.821 & 197.252 \\
\hline Lavras & 120.600 & 134.673 & 149.669 & 149.847 & 149.116 & 152.109 & 149.786 & 148.206 \\
\hline São João Del Rei & 157.396 & 171.184 & 182.696 & 186.050 & 183.695 & 193.347 & 185.854 & 182.941 \\
\hline Barbacena & 186.987 & 205.714 & 221.989 & 225.905 & 223.826 & 232.347 & 225.732 & 222.663 \\
\hline Ponte Nova & 194.911 & 190.248 & 187.147 & 185.220 & 175.647 & 214.879 & 184.422 & 180.286 \\
\hline Manhuaçu & 222.289 & 250.380 & 273.814 & 280.668 & 279.981 & 282.796 & 280.610 & 278.195 \\
\hline Viçosa & 199.267 & 215.332 & 221.585 & 232.653 & 229.246 & 243.210 & 232.369 & 228.481 \\
\hline Muriaé & 242.848 & 261.537 & 275.986 & 281.688 & 277.262 & 295.397 & 281.318 & 276.462 \\
\hline Ubá & 211.140 & 241.688 & 269.650 & 274.625 & 275.156 & 272.978 & 274.669 & 273.392 \\
\hline Juiz de Fora & 583.117 & 664.282 & 728.602 & 751.794 & 752.282 & 750.284 & 751.835 & 747.419 \\
\hline Cataguases & 193.586 & 207.389 & 216.590 & 222.271 & 218.409 & 234.239 & 221.949 & 217.945 \\
\hline
\end{tabular}

Fonte: IBGE. Censos Demográficos de 1991, 2000 e 2010; IBGE (2008).

(1) Dados projetados de Minas Gerais presentes em IBGE (2008). 


\section{Erros de distribuição}

Dada a execução dessa compatibilização, quando necessário, pode-se estimar o erro de distribuição da população. Trata-se de comparar a população projetada com aquela observada e, por meio de uma padronização das participações na população total, estimar o quanto da população projetada precisaria ser realocada para se atingir a população observada. Pode-se também utilizar essa medida de erro para comparar resultados de projeções com técnicas distintas. Alguns autores usam esse tipo de padronização para mensurar desigualdade de composição no mercado de trabalho entre categorias distintas, como sexo ou status migratório (BATISTA; CACCIAMALI, 2009). Em Economia Regional, essas medidas são empregadas para identificar e mensurar a reestruturação regional, associação geográfica ou temporal de atividades econômicas, entre outros (HADDAD, 1989). Aqui, a medida padronizada que indica o erro de distribuição é expressa como:

$E D=\frac{1}{2} \quad \sum_{i=1}^{n}\left|\frac{Z_{i}}{Z_{j}}-\frac{T_{i}}{T_{j}}\right| * 100$

Onde ED é o erro de distribuição ou fator de redistribuição; $Z i$ e $Z j$ são as populações, respectivamente, da pequena área $i$ e da grande área $j$ projetadas segundo a técnica $Z$; e Ti e $T j$ são as populações da pequena área $i$ e da grande área $j$ que foram observadas ou projetadas segundo uma técnica $T$.

Outra medida pertinente dos erros de distribuição é o coeficiente de correlação de Spearman entre a população projetada e a observada (WALDVOGEL, 1998). Esse coeficiente é um indicador de correlação de posição e serviria para comparar projeções ou mesmo a projeção com a realidade para verificar se a técnica empregada gerou alguma mudança na ordem ou hierarquia de tamanho das áreas menores. Para possuir um indicador mais claro de erro, o coeficiente foi invertido, subtraindo-o de uma unidade $\left(1-r_{s}\right)$ e apresentando-o em valores percentuais. Assim, tem-se uma ideia crescente do erro provocado por uma inferência de distribuição espacial da população, que provocou mudanças no ranking de microrregiões.

\section{Limites de aceitação}

Existe uma dificuldade latente em definir ou justificar uma margem de erro aceitável. Em geral, autores trabalham com uma margem de erro de $10 \%$, para mais ou para menos (SMITH, 1987; ÁLVAREZ, 2001; GONZÁLEZ; TORRES; CELTON, 2010; GONZÁLEZ, 2010). Alguns autores, contudo, apontam que os erros de projeção devem possuir limites de aceitação variáveis, segundo o horizonte de projeção e o tamanho da população (SMITH; TAYMAN; SWANSON, 2001; BRITO; CAVENAGHI; JANNUZZI, 2010).

Brito, Cavenaghi e Jannuzzi (2010) salientam que o limiar ideal para a margem de erro deve variar segundo o tamanho, uma vez que o crescimento de populações é mais estável se comparado com populações menores. Quanto ao tempo, os autores afirmam, em 
concordância com Smith, Tayman e Swanson (2001), que em horizontes de aproximadamente dez anos a margem de erro pode variar entre $8 \%$ e $14 \%$.

Wilson e Rowe (2011), em sua análise sobre o Reino Unido, apontam que, independentemente do tamanho da população, erros inferiores a 5\% são aceitáveis, entre 5\% e 10\% seriam considerados pequenos, entre $10 \%$ e $20 \%$ considerados moderados e superiores a $20 \%$ estariam classificados como grandes erros.

Nesse trabalho, optou-se por manter $5 \%$ como margem de erro relativo aceitável para cada unidade, buscando um equilíbrio entre o rigor aceitável para o horizonte de projeção (2000-2010) e o tamanho das microrregiões de Minas Gerais (Tabela 1).

\section{Análise dos erros de projeção}

Quando são utilizadas as medidas de erro anteriormente discutidas para as projeções elaboradas, torna-se possível constatar algumas assimetrias, como mostra a Tabela 2.

TABELA 2

Medidas de erro de projeção, segundo técnicas aplicadas às microrregiões Estado de Minas Gerais - 2010

\begin{tabular}{|c|c|c|c|c|c|c|}
\hline \multirow{2}{*}{ Técnicas } & \multirow{2}{*}{ ED (\%) } & \multirow{2}{*}{ RMS (\%) } & \multirow{2}{*}{$1-r_{s}(\%)$} & \multicolumn{3}{|c|}{ № de microrregiões } \\
\hline & & & & $E R \geq 5 \%$ & $\mathrm{ER} \leq-5 \%$ & $|E R| \geq 5 \%$ \\
\hline $\mathrm{AiBi}$ & 1,593 & 0,240 & 0,255 & 10 & 6 & 16 \\
\hline Shift-share & 2,282 & 0,310 & 0,476 & 11 & 13 & 24 \\
\hline Partição constante & 1,768 & 0,078 & 0,284 & 35 & 2 & 37 \\
\hline Extrapolação linear & 1,647 & 0,246 & 0,296 & 9 & 6 & 15 \\
\hline Extrapolação exponencial & 2,240 & 0,314 & 0,380 & 11 & 8 & 19 \\
\hline
\end{tabular}

Fonte: IBGE. Censos Demográficos de 1991, 2000 e 2010; IBGE (2008).

Nota: ED - erro de distribuição; RMS - root mean square; ER - erro relativo.

Comparando as técnicas utilizadas por meio do erro de distribuição (ED), observa-se que AiBi é a mais compatível com a distribuição da população entre as microrregiões observada em 2010, sendo a técnica shift-share a menos verossímil, juntamente com a extrapolação exponencial. De todo modo, erros de distribuição abaixo de 2,5\% podem ser considerados razoáveis para este indicador.

Quando analisado o valor quadrático médio dos erros (root mean square ou RMS), em percentual da população observada, constata-se que a partição constante possui o melhor indicador, ou seja, menor percentual de erro. Vale lembrar que a RMS salienta os maiores desvios, mas não evidencia a direção dos erros nem a distribuição dos mesmos. Ainda assim, shift-share e a extrapolação exponencial continuam a ser as duas técnicas com indicadores menos favoráveis.

Uma vez mais, AiBi mostrou-se como a técnica com menor erro, seguida pela partição constante e extrapolação linear. Nota-se, também, que shift-share e a extrapolação exponencial apresentaram indicadores piores em relação às demais técnicas experimentadas. A técnica AiBi utiliza a partição do crescimento, ao passo que as demais são função do 
tamanho populacional. Assim, os resultados podem apresentar idiossincrasias do estudo de caso, pela dimensão das unidades e pelo comprimento do horizonte de projeção, não havendo garantias de que outras unidades espaciais tenham o mesmo comportamento.

FIGURA 1

Distribuição espacial dos erros relativos de projeção por diferentes técnicas de extrapolação matemática, segundo microrregiões

Estado de Minas Gerais - 2010
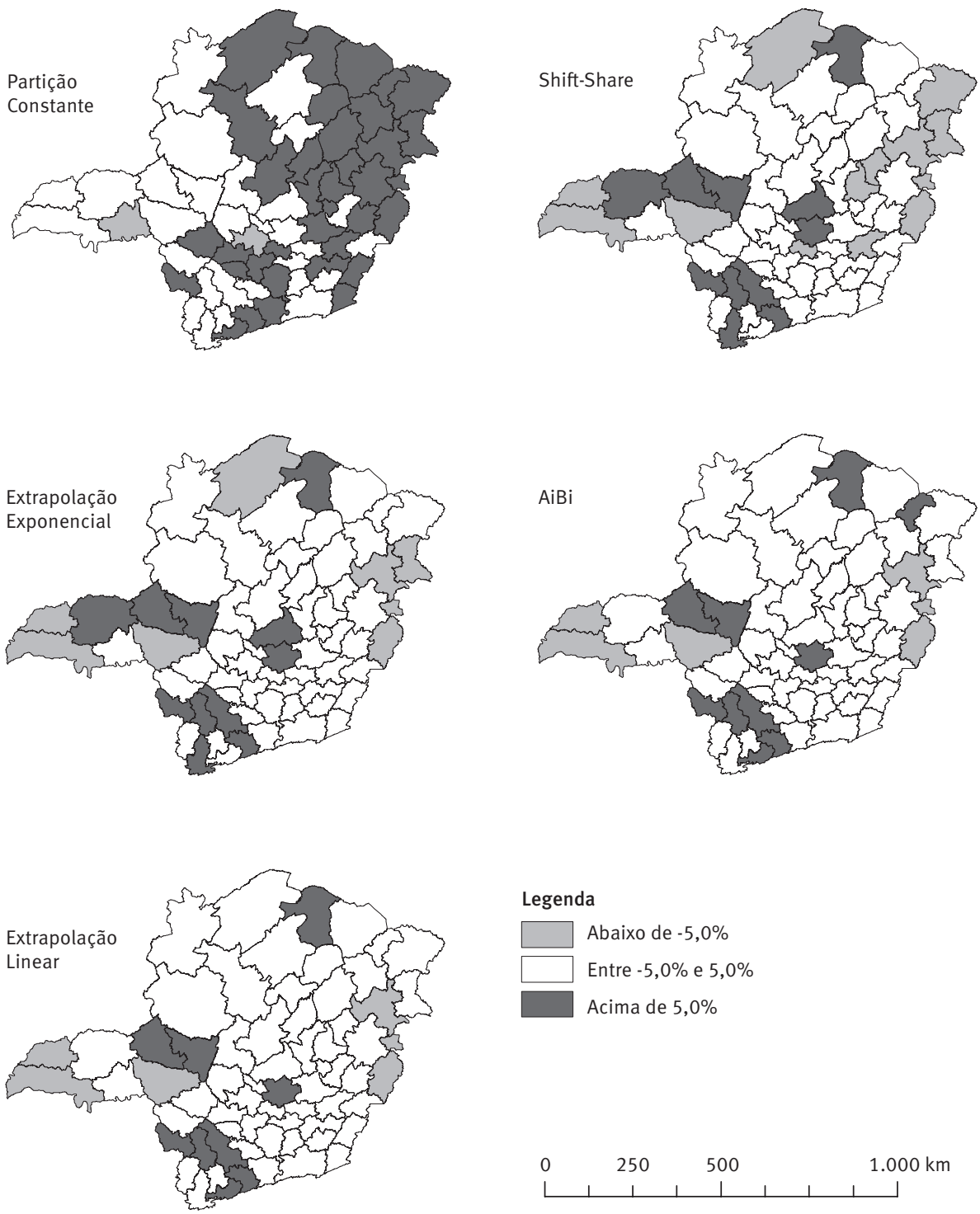

Legenda
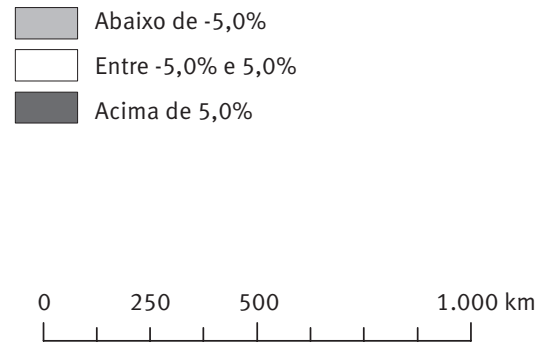

Fonte: IBGE. Censos Demográficos de 1991, 2000 e 2010; IBGE (2008).

Por fim, consideraram-se também os erros relativos de cada microrregião (ER), ou seja, a razão entre o desvio absoluto (população projetada subtraída a população observada) e 
a população observada. Admitindo-se um erro relativo em módulo de $5 \%$ como razoável, contabilizaram-se aquelas microrregiões que apresentam, para cada técnica, valores para além desse limiar. Os resultados mostram que a partição constante possui o maior número de microrregiões com valor igual ou superior a 5\% de erro relativo em módulo.

Extrapolação linear e AiBi apresentaram um número menor de microrregiões nessa situação, com uma distribuição também mais equilibrada entre valores acima de $5 \%$ e abaixo de $-5 \%$. Vale também a observação de que valores acima de $5 \%$ indicam que as projeções registraram valores acima dos observados em 2010, e projeções abaixo de $-5 \%$ de erro relativo tiveram valores inferiores aos observados. Projeções com erros entre $-5 \%$ e $5 \%$ foram consideradas razoáveis para este exercício. As técnicas de extrapolação exponencial e shift-share, uma vez mais, mostraram-se como as menos confiáveis a partir dos indicadores de erro de projeção.

Avaliando a Figura 1, que apresenta os mapas com a distribuição espacial dos desvios em relação à população observada por microrregiões, pode-se inferir que existe maior concentração dos erros acima de $5 \%$ nas microrregiões mais meridionais do Estado, ao passo que na região do Triangulo Mineiro e Nordeste os erros tendem a ser menores que $-5 \%$. Pode-se levantar a hipótese de desaceleração, na qual regiões que possuíam maior tendência de crescimento no sul cresceram menos, ao passo que as regiões que costumavam perder população ou participação tiveram menos perdas na última década, influenciando as projeções que seguiam as tendências da década de 1990. Ressalta-se que a partição constante parece ter uma distribuição pouco aderente a esta hipótese, mas que indica uma inconsistência do pressuposto de participação constante no tempo e no espaço, comparando com as demais técnicas apresentadas nos mapas da Figura 1.

Partiu-se da hipótese de que os erros relativos considerados elevados (acima de $5 \%$ ou abaixo de -5\%) para essas microrregiões não decorrem de baixa precisão da projeção do crescimento natural, mas sim dos efeitos da migração. Essa hipótese apoia-se, essencialmente, no fato de a migração ser uma componente de difícil controle em projeções em função de sua sensibilidade a variações econômicas, ambientais e sociais. Além disso, grande parte das microrregiões com erros altos, especialmente no Triângulo Mineiro e sul de Minas, apresentou elevado dinamismo econômico na primeira década deste século, o que certamente contribui para a instabilidade das projeções de migração.

Para testar essa hipótese, realizou-se um teste de correlação de Pearson entre migração e algumas variáveis que poderiam indicar uma fonte de instabilidade, a saber, número de imigrantes, emigrantes, saldo migratório, taxa líquida de migração, população total e taxas de crescimento médio (resultados não apresentados nesse artigo).

As informações sobre migração foram retiradas do Censo de 2000 (variáveis de estoque populacional ou "data-fixa") e as taxas de crescimento referem-se aos Censos de 1991, 2000 e 2010. Os resultados identificaram uma moderada associação entre os erros de projeção das diferentes técnicas empregadas e as variáveis de migração $\left(r_{\text {pearson }}\right.$ com valores entre 0,3 e 0,7 com nível de significância 0,05), o que corrobora razoavelmente 
a hipótese do efeito da mobilidade sobre os erros altos verificados nas microrregiões indicadas na Figura 1.

Destaca-se, por fim, ${ }^{11}$ a microrregião de Belo Horizonte, apresentando com frequência erros de projeção acima de $5 \% .0$ declínio do crescimento de municípios pertencentes a essa microrregião em relação à década de 1990 pode ser a causa desse indicador, lembrando que a principal fonte de instabilidade de pequenos domínios é a componente migração.

\section{Considerações finais}

O objetivo deste trabalho foi apresentar e discutir algumas técnicas de projeção de pequenas áreas e exemplos de aplicação, bem como a discussão de seus limites a partir de alguns indicadores de erros de projeção. Os resultados mostram que técnicas como partição do crescimento, ou AiBi, são mais verossímeis por não serem diretamente determinadas pelo tamanho da população, mas sim pela participação das pequenas áreas no crescimento da área maior.

Salienta-se que as projeções utilizando a técnica AiBi tendem a ser mais precisas quando: i) o erro de projeção da grande área é pouco significante ou pequeno; ii) a população da pequena área possui uma relação aproximadamente constante entre o seu crescimento e o da grande área; ii) comparando o conjunto das projeções, existe um número menor de pequenas áreas, sendo cada fração mais determinante no comportamento do crescimento da grande área; iii) independentemente do número de áreas, as relações são constantes entre os dois níveis hierárquicos; iv) não há diferenças muito grandes entre as dimensões das pequenas áreas, pois nestes casos as menores, entre as pequenas áreas, tenderiam a se distanciar mais da grande área em termos de tendência.

Por outro lado, a aderência das projeções definidas pela função linear às informações sobre a população observada em 2010 pode ser explicada pela precisão da técnica em intervalos de tempo ou horizontes de projeção menores. Esse efeito é esperado em qualquer técnica de projeção aplicada e, no caso das microrregiões de Minas Gerais, parece indicar uma idiossincrasia no período observado. Mesmo que uma função não linear descreva melhor a tendência histórica de uma população que sofra um processo de desaceleração e aproxima de zero, a dimensão do horizonte acaba por aproximar o comportamento de crescimento dessa população a uma função linear.

Erros de projeção ocorrerão sempre, mas erros maiores para além de limiares considerados aceitáveis devem-se à instabilidade da população, ou a limitações técnicas. Assumindo que as técnicas foram aplicadas com razoável precisão, cabe apresentar algumas possíveis fontes de instabilidade que limitam o uso dessas técnicas, a saber, os efeitos dimensionais, temporais e espaciais. Vale ressaltar o pressuposto aqui assumido de que a

\footnotetext{
11 Apesar de não ser objeto da discussão central, vale destacar que o erro médio das projeções do IBGE (2008) para o Brasil, em 2010, foi de 1,31\%, ao passo que para o Estado de Minas Gerais foi de 3,12\%. 0 ED para a projeção do país por UF foi de $0,73 \%$, RMS de $0,122 \%$ e apenas duas Unidades Federativas apresentaram valores de erros relativos acima de $5 \%$ em módulo: Bahia (5,34\%) e Tocantins (-5,81\%).
} 
população observada seja, de fato, a população real, descartando a possibilidade de que os erros de cobertura censitária sejam o motivo das dissonâncias ou erros de precisão.

0 efeito dimensional refere-se ao tamanho da unidade a ser projetada. Como já apontado, quanto menor for o tamanho da população, maiores serão a variância e, consequentemente, 0 erro. A escolha por microrregiões determina que o erro seja menor por se tratar de conjuntos de municípios. Na prática, as técnicas de projeções de pequenas áreas são exigidas para a projeção de municípios ou distritos, o que eleva os indicadores de erro de projeção. Tal elevação é intuitiva, pois, ao considerar que indivíduos são unidades irredutíveis de uma população, a menor dimensão do conjunto aumenta a variabilidade do tamanho populacional ao longo do tempo, ampliando o impacto que oscilações das componentes demográficas têm sobre 0 crescimento. Quando aplicadas algumas medidas de correlação entre tamanho populacional e erros relativos e absolutos de projeção, não foram encontrados valores significativos que comprovem essa hipótese para as microrregiões neste exercício.

0 efeito temporal refere-se à influência do período base e do horizonte de projeção nos valores finais a serem determinados. Sabe-se que os erros tendem a aumentar quanto maior for o horizonte de projeção. Como metáfora, o efeito dimensional seria fazer com que qualquer objeto torne-se tão diminuto até dificultar a identificação de sua forma. 0 efeito temporal seria como colocar o mesmo objeto a uma distância tal que as formas ficariam similares e não identificáveis, até se tornar um ponto. 0 contrário também é verdadeiro, pois, em horizontes reduzidos, os erros de projeção tendem a ser menores e, no limite, intervalos pequenos assemelham-se a crescimentos lineares da população, parte do que expressa o comportamento dos resultados desse artigo.

Porém, o efeito temporal possui outro elemento, ou seja, as mudanças históricas não observáveis em modelos matemáticos de predição. Isso acontece quando o horizonte de projeção apresenta ocorrências reestruturantes que provocam determinações no crescimento populacional e que não foram observadas, ou consideradas, na identificação do período base. Neste exercício, o intervalo de dez anos talvez não tenha sido suficiente para mudanças significativas de redistribuição espacial da população, ou mesmo no seu ritmo de crescimento, explicando porque a extrapolação linear encontrou resultados razoáveis neste exercício. Em verdade, vale também notar que, mantendo o intervalo ou horizonte de projeção constante, num cenário de redução do ritmo de crescimento populacional, as projeções feitas por ajuste de equações lineares tendem a se ajustar cada vez melhor.

Por fim, o efeito espacial refere-se à influência de elementos espaciais exógenos às técnicas aqui apresentadas. Os mapas permitem inferir certa associação espacial dos erros de algumas técnicas, possivelmente influenciadas por uma convergência do crescimento populacional. A hipótese de convergência seria plausível se a proximidade das taxas de crescimento microrregionais em relação à da Unidade Federativa fosse significativamente correlacionada aos erros de projeção, o que não é verdade $\left(r_{\text {pearson }}<0,30\right)$.

Vale ressaltar o efeito espacial possível a partir de redistribuição de fatores determinantes do crescimento populacional, ou seja, mudança na distribuição dos fatores de 
produção ou, em sentido mais amplo, dos fatores de atração e repulsão. Essas mudanças espaciais, de tendências de crescimento ou de mudanças não tendenciais, provocam fortes alterações no crescimento da população em suas partes e em sua totalidade (SANTOS, 2010). Dessa forma, mudanças histórico-geográficas não são passíveis de identificação exata por métodos formais, todavia suas informações são elementos sensíveis que podem ser captados e incorporados nos ajustes das projeções.

Em suma, destaca-se que estas diferenças entre população projetada e observada ocorrem por efeitos para além das estruturas das técnicas, sendo que seus efeitos puros são difíceis de captar, mesmo por modelos mais sofisticados. Para análise regional e demandas de diagnóstico, estas técnicas atendem a necessidades imediatas, guardadas suas limitações, mas deve-se recordar que a população, como qualquer totalidade, é mais do que a soma das partes. Ainda que seja um conceito quantitativo, população possui determinantes que não são hierarquicamente constitutivos, sendo também por isso necessário o diálogo entre cientistas sociais de várias áreas para a construção de projeções mais sensíveis à realidade que se tenta entender e retratar.

\section{Referências}

ÁLVAREZ, G. Estimación de población en áreas menores mediante variables sintomáticas: una aplicación para los departamentos de la República Argentina (1991 y 1996). Santiago: Cepal, 2001. (Série Población y Desarrollo).

ATCHLEY, R. C. Population projections and estimates for local areas. Ohio: Miami University, 1970.

BARBIERI, A. F.; SANTOS, R. O. Projeção demográfica de pequenas áreas integrada a projeções econômicas: um estudo de cenários de migração para região do Alto Paraopeba, Minas Gerais. Revista Paranaense de Desenvolvimento, v. 121, p. 13-33, 2011.

BARBIERI, A. F. Mobilidade populacional, meio ambiente e uso da terra em áreas de fronteira: uma abordagem multiescalar. Revista Brasileira de Estudos de População, v. 24, n. 2, p.225246, jul./dez. 2007.

BATISTA, N. F. B.; CACCIAMALI, M. C. Diferencial de salários entre homens e mulheres segundo a condição de migração. Revista Brasileira de Estudos de População, v. 26, n. 1, p. 97-115, jan./ jun. 2009.

BIJAK, J. Forecasting international migration: selected theories, models and methods. Warsaw: CEFMR, 2006. (Working paper, 4/2006). Disponível em: 〈http://www.cefmr.pan.pl/docs/ cefmr_wp_2006-04.pdf〉. Acesso em: 02 jan. 2009.

BRITO, L. P. G.; CAVENAGHI, S.; JANNUZZI, P. Estimativas e projeções populacionais para pequenos domínios: uma avaliação da precisão para municípios do Rio de Janeiro em 2000 e 2007. Revista Brasileira de Estudos de População, v. 27, n. 1, p. 35-57, jan./jun. 2010.

CASTRO, I. E. O problema da escala. In: CASTRO, I. E.; GOMES, P. C. C.; CORRÊA, R. L. Geografia: conceitos e temas. Rio de Janeiro: Bertrand Brasil, 2002. p. 115-140.

CAVENAGHI, S. (Org.). Estimaciones y proyecciones de población en América Latina. Desafíos de una agenda pendiente. Rio de Janeiro: Alap, 2012. 
DUCHESNE, L. Proyeciones de poblacion por sexo y edad para areas intermedias y menores. Santiago: Centro Latinoamericano de Demografia, 1987.

FÍGOLI, M. G. B.; ESPINOZA, L. L. R.; GONZAGA, M.; GOMES, M. M. F. Aspectos metodológicos para a projeção de localidades intra-urbanas uma aplicação a Minas Gerais. In: XVII ENCONTRO NACIONAL DE ESTUDOS POPULACIONAIS 2010. Anais... Caxambu: Abep, 2010.

GIBSON, C. C. et al. The concept of scale and the human dimensions of global change: a survey. Ecological Economics, v. 32, n. 2, p. 217-239, Jul. 2000.

GIOVANINI, R. R. Regiões em movimento: um olhar sobre a Geografia Histórica do Sul de Minas e da Zona da Mata mineira (1808-1897). Dissertação (Mestrado) - Instituto Geociências - IGC/ Universidade Federal de Minas Gerais - UFMG, Belo Horizonte, 2006.

GOMES, M. M. F.; GONZAGA, M.; UMBELINO, G. M.; FÍGOLI, M. G. B.; RODRIGUES, R. N. O "sertão nordestino" mineiro: caracterização e projeção populacional das microrregiões do Vale do Jequitinhonha, 2000-2030. In: XIV SEMINÁRIO SOBRE A ECONOMIA MINEIRA. Anais... Diamantina, 2010.

GONZÁLEZ, L. M. Ajuste de proyecciones de poblaciones menores con variables sintomáticas. El caso del Gran Córdoba (Argentina), 2001-2016. Notas de Población, n. 91, p. 105-28, 2010.

GONZÁLEZ, L. M.; TORRES, E.; CELTON, D. Estimación de la población de áreas subprovinciales con variables sintomáticas. Córdoba (Argentina). In: IV CONGRESO DE LA ASOCIACIÓN LATINOAMERICANA DE POBLACIÓN. Havana: Alap, 2010.

GONZÁLEZ, L. M.; TORRES, E. Estimaciones de población en áreas menores en América Latina: revisión de métodos utilizados. In: CAVENAGHI, S. (Org.). Estimaciones y proyecciones de población en América Latina. Desafíos de una agenda pendiente. Rio de Janeiro: Alap, 2012.

HADDAD, P. R. Medidas de localização e de especialização. In: HADDAD, P. R.; FERREIRA, C. M. C.; BOISER, S.; ANDRADE, T. A. Economia Regional: teorias e métodos de análise. Fortaleza: BNB, 1989. p. 225-247 (Estudos Econômicos e Sociais, 36).

IBGE - Instituto Brasileiro de Geografia e Estatística. Censo demográfico de 1991: Brasil. Rio de Janeiro: IBGE, 1991.

. Censo demográfico de 2000: Brasil. Rio de Janeiro: IBGE, 2000.

Censo demográfico de 2010: Brasil. Rio de Janeiro: IBGE, 2010.

Projeção da população do Brasil por sexo e idade, 1980 a 2000: revisão 2008. Rio de Janeiro: IBGE, 2008 (Série Estudos e Pesquisas: Informação Demográfica e Socioeconômica, n. 24).

IPARDES - Instituto Paranaense de Desenvolvimento Econômico e Social. Projeções de população por sexo e idade 1991-2020. Curitiba: Ipardes; Rio de Janeiro: IBGE, 1999.

ISNARD, W. Methods of regional analysis: introduction to regional sciences. Cambridge: M.I.T. Press, 1960.

JANNUZZI, P. M. Cenários futuros e projeções populacionais para pequenas áreas: método e aplicação para distritos paulistanos 2000-2010. Revista Brasileira de Estudos de População, v. 24, n. 1, p. 109-137, 2007.

Projeções populacionais para pequenas áreas: método e aplicações. Rio de Janeiro: Escola Nacional de Ciências Estatísticas, 2006 (Textos para discussão, 22).

JARDIM, M. de L. T. Metodologias de estimativas e projeções populacionais para áreas menores: a experiência do Rio Grande do Sul. In: ENCONTRO NACIONAL DE ESTUDOS POPULACIONAIS, 12. Anais... Caxambu: Abep, 2000. 
KEYFITZ, N. The limits of population forecasting. Population and Development Review, v. 7, n. 4, p. 579-593, Dec. 1981.

MADEIRA, J. L.; SIMÕES, C. C. S. Estimativas preliminares da população urbana e rural segundo as unidades da Federação, 1960/1980: por uma nova metodologia. Revista Brasileira de Estatística, v. 33, n. 129, p. 3-11, jan./mar. 1972.

MATOS, R. E. S.; GARCIA, R. A. Espacialidade dos PIB e da migração em Minas Gerais. In: X SEMINÁRIO SOBRE A ECONOMIA MINEIRA. Anais... Diamantina: Cedeplar/UFMG, 2006.

O’NEIL, B. C.; BALK, D.; BRICKMAN, M.; EZRA, M. A guide to global projections. Demographic Research, v. 4, p. 203-288, Jun. 2001.

PRESTON, S.; HEUVELINE, P.; GUILLOT, M. Demography: measuring and modeling population processes. Malden, Massachussets: Blackwell Publishers, 2001.

REES, P. H. Population projection for development planning. In: UNITED NATIONS. Population and development planning. New York: Department of Economic and Social Development, 1993.

ROGERS, A. Regional population projection models. Beverly Hills: Sage, 1985.

SANTOS, R. O. Projeções populacionais para pequenas áreas a partir de cenários econômicos: aplicação de ratio methods para a região do Alto Paraopeba-MG, 2010-2025. Dissertação (Mestrado) - Cedeplar/UFMG, Belo Horizonte, 2010.

SMITH, S. K. Population projections: what do we really know? Florida: University of Florida, 1984 (BEBR Monographs).

Tests of forecast accuracy and bias for county population projections. Journal of the American Statistical Association, v. 82, n. 400, p. 991-1003, 1987.

SMITH, S. K.; MORRISON, P. A. Small-area and business demography. In: POSTON, D.; MICKLIN, D. (Eds.). Handbook of population. New York: Springer Publishers, 2005.

SMITH, S. K.; SHAHIDULLAH, M. An evaluation of population projection errors for census tracts. Journal of the American Statistical Association, v. 90, p. 64-71, Mar. 1995.

SMITH, S. K.; TAYMAN, J.; SWANSON, D. A. State and local population projections: methodology and analysis. New York: Kluwer: Plenum, 2001.

STOTO, M. The accuracy of population projections. Journal of the American Statistical Association, v. 78, p. 13-20, Mar. 1983.

SWANSON, D. A.; SCHLOTTMANN, A.; SCHMIDT, B. Forecasting the population of census tracts by age and sex: an example of the hamilton-perry method in action. Population Research and Policy Review, v. 29, n. 1, p. 47-63, Feb. 2010.

SZWARCWALD, C. L.; CASTILHO, E. A. Proposta de um modelo para desagregar projeções demográficas de grandes áreas em seus componentes geográficos. Revista Saúde Pública, v. 23, p. 269-276, ago. 1989.

UNITED NATIONS. Manual VIII. Methods for projections of urban and rural. New York, 1974.

Population and Development Planning. New York: Department of Economic and Social Development, 1993.

. Manual III. Methods for population projections by sex and age. New York: Department of International Economic and Social Affairs, 1956.

New York, 1989

Projection methods for integrating population variables into development planning. 
VAINER, C. B. As escalas do poder e o poder das escalas: o que pode o poder local? Cadernos IPPUR, n. 2001-2/2002-1, p.13-32, 2002.

WALDVOGEL, B. Técnicas de projeção populacional para o planejamento regional. Belo Horizonte: UFMG/Cedeplar, 1998. (Estudos Cedeplar, n. 1).

WALDVOGEL, B.; CAPASSI, R. Projeção populacional como instrumento de planejamento regional: o caso do Estado de São Paulo. In: XI ENCONTRO NACIONAL DE ESTUDOS POPULACIONAIS. Anais... Belo Horizonte: Abep, 1998.

WILSON, T.; ROWE, F. The forecast accuracy of local government area population projections: a case study of Queensland. Australasian Journal of Regional Studies, v. 17, n. 2, p. 204-243, 2011.

WRIGHT, J. T. C.; GIOVINAZZO, R. A. D. Delphi: uma ferramenta de apoio ao planejamento prospectivo. Caderno de Pesquisas em Administração, v.1, n. 12, 2ํㅡㄴ trimestre 2000.

\title{
Sobre os autores
}

Reinaldo Onofre dos Santos é doutorando em Demografia no Centro de Desenvolvimento e Planejamento Regional - Cedeplar, da Universidade Federal de Minas Gerais - UFMG. Gerente de planejamento e análise de informações da Prefeitura de Belo Horizonte-MG.

Alisson Flávio Barbieri é PhD em Planejamento Urbano e Regional pela University of North Carolina at Chapel Hill, EUA. Professor associado do Departamento de Demografia e Pesquisador do Centro de Desenvolvimento e Planejamento Regional - Cedeplar, da Universidade Federal de Minas Gerais - UFMG.

\section{Endereço para correspondência}

Cedeplar-Face-UFMG

Av. Antônio Carlos, 6627

31270-901 - Belo Horizonte-MG, Brasil

\begin{abstract}
Population projections for small areas: a comparative assessment of mathematical extrapolation techniques
\end{abstract}

Understanding future scenarios of population size and distribution is a key aspect in regional analysis and planning. The main objective of this paper is to critically discuss some mathematical extrapolation techniques frequently used for projection in small areas, in order to contribute to the analytical instruments of demographers and planners. Population projections for small areas pose a challenge for planners due to the instability of the predictions and the conflict with the pressing need for formulating public policies. Thus, this paper presents the application of five projection techniques for small areas, as well as some error measures, comparing the projections made for the 2010 Minas Gerais micro-regions with the reality observed in the Demographic Census carried out in the same year. The results show the reliability of simple projection techniques in the short term. The discrepancies between projected and observed populations are due to dimensional, spatial, and temporal effects that cannot be measured exactly, but which do not invalidate their utilization since when the limitations are known and taken into account.

Keywords: Population projections. Small areas. Demographic techniques. Minas Gerais. 


\section{Resumen}

Proyecciones de población en áreas pequeñas: una evaluación comparativa de técnicas de extrapolación matemática

La investigación del tamaño y la distribución futuros de una población tiene una importancia fundamental para los estudiosos de la población que se ocupan de cuestiones relacionadas con la planificación regional. El objetivo central de este artículo es discutir, de forma crítica y propositiva, algunas técnicas de extrapolación matemática utilizadas frecuentemente para la proyección en áreas pequeñas, con el propósito de contribuir con los instrumentos de análisis de los demógrafos y los planificadores. Las proyecciones de población para áreas pequeñas son un desafío para los planificadores, en función de la inestabilidad de sus predicciones y del conflicto con su necesidad eminente para la construcción de políticas públicas. Este trabajo presenta la aplicación de cinco técnicas de proyección para áreas pequeñas y algunas medidas de error, confrontando las proyecciones realizadas para las microrregiones mineras en 2010 con la realidad observada en el censo demográfico del país ese mismo año. Los resultados muestran que las técnicas simples de proyección se ajustan a la realidad en el corto plazo. Se señala que las discordancias presentes entre las proyecciones y la realidad observada se deben a los efectos dimensionales, temporales y espaciales que las técnicas no logran medir con exactitud, pero que no invalidan su uso a partir del conocimiento de sus limitaciones.

Palabras clave: Proyecciones de población. Áreas pequeñas. Técnicas demográficas. Minas Gerais. 
